\title{
NAVEGAÇÃO E LEITURA DE HIPERTEXTO DIGITAL E IMPRESSO
}

Vânia Carvalho de Castro

\section{RESUMO}

Partindo-se do pressuposto de que desde o aparecimento das tecnologias digitais na contemporaneidade as práticas sociais de leitura têm passado por mudanças, esta pesquisa apresenta uma análise de navegação e trajetos de leitura em uma revista digital e essa mesma impressa. Para tanto, foram realizados testes de leitura com um grupo de leitores. Tais testes ajudaram a compreender como eles lidam com diferentes organizações textuais e como se comportam no decorrer do processo de leitura. A revista escolhida para análise foi a Superinteressante. Para melhor qualificar esta pesquisa algumas observações foram realizadas durante os testes com os leitores. Tais observações foram seguidas de anotações e gravações em tempo real. Como suporte teórico, este estudo baseia-se nas pesquisas de Coscarelli (2009, 2010), Novaes (2009), Ribeiro (2009), entre outros. Apresento um levantamento do experimento e parece ser possível que, mesmo os meios digitais estarem inseridos na sociedade e que não existem leitores "novatos" nesses ambientes, é necessário que os leitores, com pouca experiência, adquiram habilidades de navegação que são imprescindíveis para uma busca de informação mais apurada e efetiva.

Palavras-chave: Leitura. Navegação. Texto digital e impresso.

\section{INTRODUÇÃO}

Com o advento e o desenvolvimento das tecnologias, vivemos e convivemos também em ambientes digitais, produzindo, lendo, preenchendo e trocando diversos gêneros textuais em situações que têm se tornado cada vez mais corriqueiras, Coscarelli Novaes (2012, p. 69). Sendo assim, a incorporação dos meios digitais na contemporaneidade tem levado o leitor a novas formas de interação e navegação, 
causando $o$ ato de lidar com esses novos hipertextos eletrônicos um desafio, pois eles se reconfiguram no passar do tempo.

Observa-se que "muitos dos textos que hoje circulam na sociedade são materializados em ambientes digitais, e é preciso que os indivíduos construam habilidades para lidar com esses textos", Dias e Novaes (2009, p. 3). É preciso saber lidar com a interface desses textos materializados e principalmente saber navegar e buscar informações neles. Esses textos se transformam em novos objetos de leitura e segundo Ribeiro (2008, p. 17) esses novos objetos podem trazer "muitas angústias, dúvidas e questões. É comum que os angustiados vejam na nova máquina certa ameaça, mais especificamente acusem de deslumbramento quem faz uso dela em detrimento do papel".

Nesse contexto, muitos leitores preferem ler textos no formato impresso e outros preferem ler textos na tela do computador. Assim, surgem as indagações: Os leitores de textos impressos são bons navegadores em textos de ambientes digitais? Os leitores de textos digitais são bons navegadores em textos impressos?

Considerando esse panorama, o objetivo desta pesquisa é analisar como um grupo de quatro leitores de diferentes perfis navega e lê hipertextos na revista digital e impressa. Para tanto, foram realizadas observações nos trajetos de leitura e navegação dos leitores nas duas versões da revista Superinteressante, online e impressa.

\section{LEITURA E NAVEGAÇÃO EM HIPERTEXTOS}

Partindo da ideia que a leitura de textos verbais demanda leituras diferentes dependendo de cada texto, gênero e situação de leitura, considero que "ler é diferente de navegar e todo leitor é navegador" destaca Coscarelli (2010). Além disso, saber navegar nos ambientes digitais, hoje, é uma habilidade imprescindível.

A leitura deve ser entendida como uma prática social, um processo ativo e dinâmico. Coscarelli e Novaes (2010, p. 3) definem leitura "como leitura verbal hipertextual não linear e um sistema complexo, não por ser complicada, mas por ser realizada de forma dinâmica, aberta, recursiva, gerando estruturas emergentes nem sempre previsíveis". Considerando o panorama desta pesquisa em leitura de texto impresso e digital, ela será vista aqui a partir da linguagem verbal. 
Para Kleiman (2004) citado em Campos (2008, p.3), a leitura é uma atividade complexa devido aos múltiplos processos cognitivos utilizados pelo leitor ao construir o sentido de um texto, já que ela "não se dá linearmente, de maneira cumulativa, em que a soma do significado das palavras constituiria o significado do texto".

Para Ribeiro (2008, p. 78):

Ler é uma atividade que aciona conhecimentos de vários tipos e, embora as pesquisadoras mencionem uma série de pistas textuais e, mais amplamente, sígnicas para o leitor "colher" enquanto (e quando) lê, raramente lembram-se da avaliação muito mais sutil que o leitor faz dos trajetos propostos (e percebidos ou não) pelo projeto gráfico, pela forma que tem o objeto de ler.

Navegar será visto neste estudo como uma habilidade de procura e seleção de informações que diferem no ambiente impresso e no digital, pois "sair do papel e ir para uma página digital vai modificar a forma de navegação naquele texto, mas nem sempre essa mudança é tão radical assim, por pelo menos dois motivos: um deles é que nenhum texto é linear e o segundo é que nenhuma leitura é linear", Coscarelli (2006, p. 1).

Beiguelman (2003) citado em Ribeiro (2008, p. 89), "navegar tem muito mais relação com percorrer uma trajetória orientada e precisa, estudada e estruturada, do que a idéia de simplesmente "andar" a esmo, que seria to browse."

Muitos pesquisadores afirmam que existem textos lineares, que a sintaxe é linear e que hipertexto é apenas digital. Para Magda (2002, p. 150):

O texto no papel é escrito e é lido linearmente, seqüencialmente - da esquerda para a direita, de cima para baixo, uma página após a outra; o texto na tela - o hipertexto - é escrito e é lido de forma multilinear, multiseqüencial, acionando-se links ou nós que vão trazendo telas numa multiplicidade de possibilidades, sem que haja uma ordem predefinida.

Coscarelli defende que expressões como "acima", "abaixo", "no quadro ao lado" são elementos no texto que dizem que o texto não é linear.

Em seus estudos sobre hipertexto, Snyder (2006) citado em Marchuschi (2001, p. 96) aponta que "diferentemente do texto impresso, que em geral compele os leitores a lerem numa onda linear da esquerda para a direita e de cima para baixo, na página- hipertextos encorajam os leitores a moverem-se de um bloco de texto a outro, rapidamente e não-seqüencialmente”. Assim, Marchuschi (2001, p. 90) ao discutir o hipertexto um novo espaço da escrita afirma que "cada texto é 
autônomo e tem proporções muito pequenas. Claro que só imitam a possibilidade da leitura não-linear, mas não conseguem reproduzir as condições do espaço virtual".

\section{A REVISTA SUPERINTERESSANTE}

A Superinteressante, também conhecida por Revista dos Infográficos, faz parte do grupo Editora Abril e já existe há 25 anos. A revista aborda assuntos como comportamento, cultura, saúde, tecnologia, futuro, história, aventura, ciência e possui as versões impressa e digital. A revista circula mensalmente em todo o território nacional e também é exportada. Segundo informações contidas na Revista Super Interessante (2004), em 2002, a Universidade de Navarra, Espanha, considerou a Super a revista que mais bem usa infográficos no mundo.

No site da revista, o leitor tem acesso ao acervo completo clicando no link SUPERARQUIVO, porém não é possível encontrar todas as reportagens de todas as edições, além disso, as matérias da revista impressa possuem formatos e organizações textuais diferentes da versão digital.

$\mathrm{Na}$ revista impressa, as reportagens possuem mais cores e mais imagens que na versão digital e o sumário segue uma dinâmica bastante diferente e em forma de infográfico.

O infográfico é um texto multimodal, ou seja, que integra modalidades semióticas bastante utilizado pelo jornalismo em notícias e reportagens de divulgação científico-tecnológica. Dionísio (2006) citado em Paiva (2011, p. 88) define infográfico como "criação gráfica que utiliza recursos visuais (desenhos, fotografias, tabelas etc.), conjugados a textos curtos para apresentar informações jornalísticas de forma sucinta e atraente". 


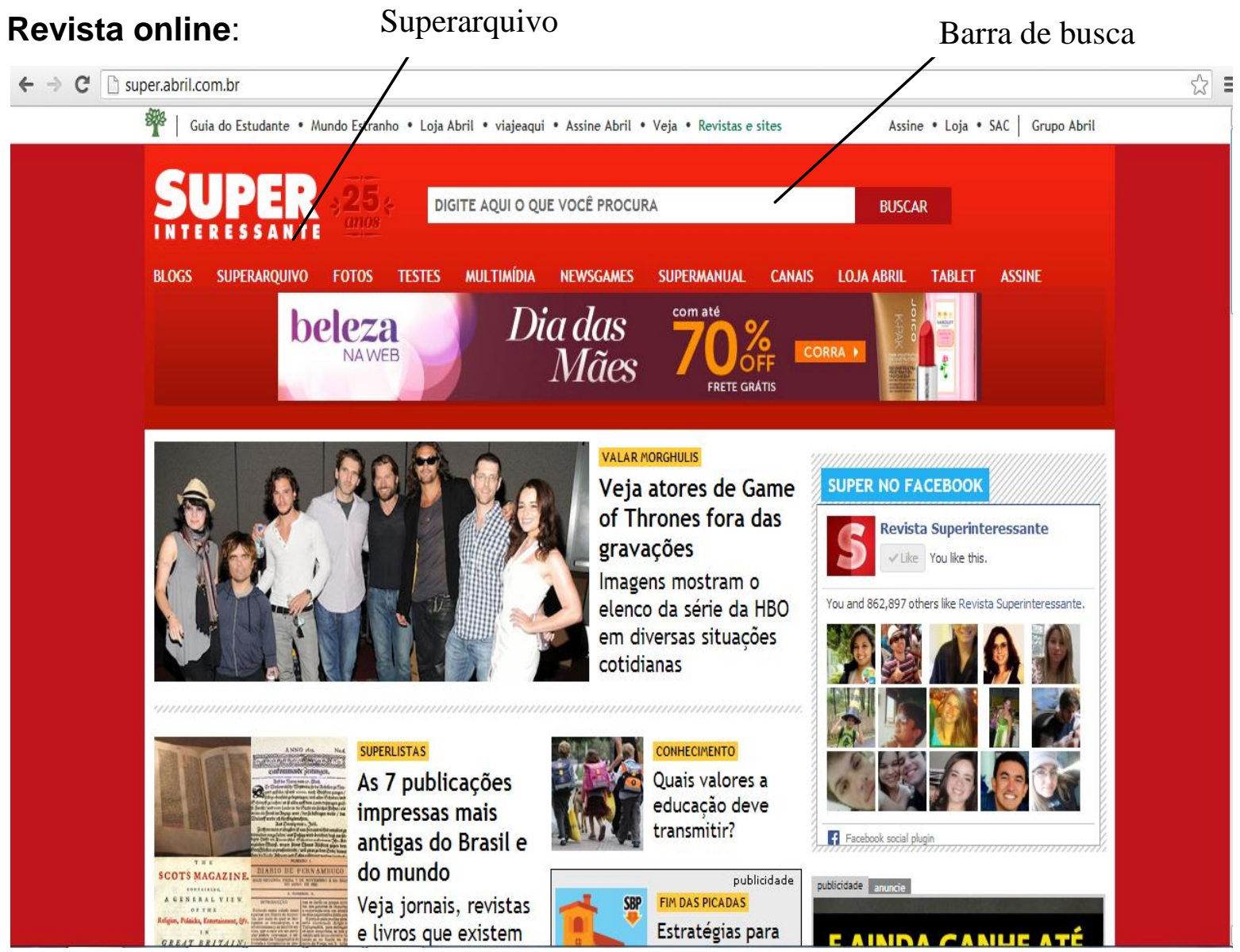

Figura 1 - Homepage da revista online

\section{Revista impressa:}

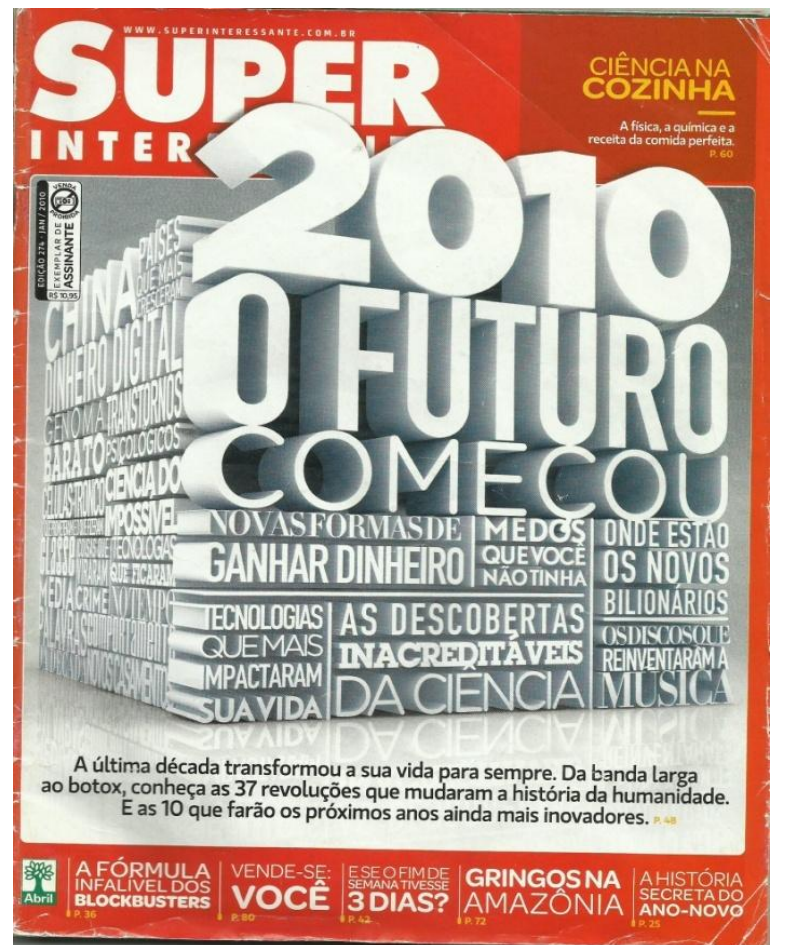

Figura 2 - Capa da revista impressa - edição 274 - Jan/2010. 


\section{Sumário}
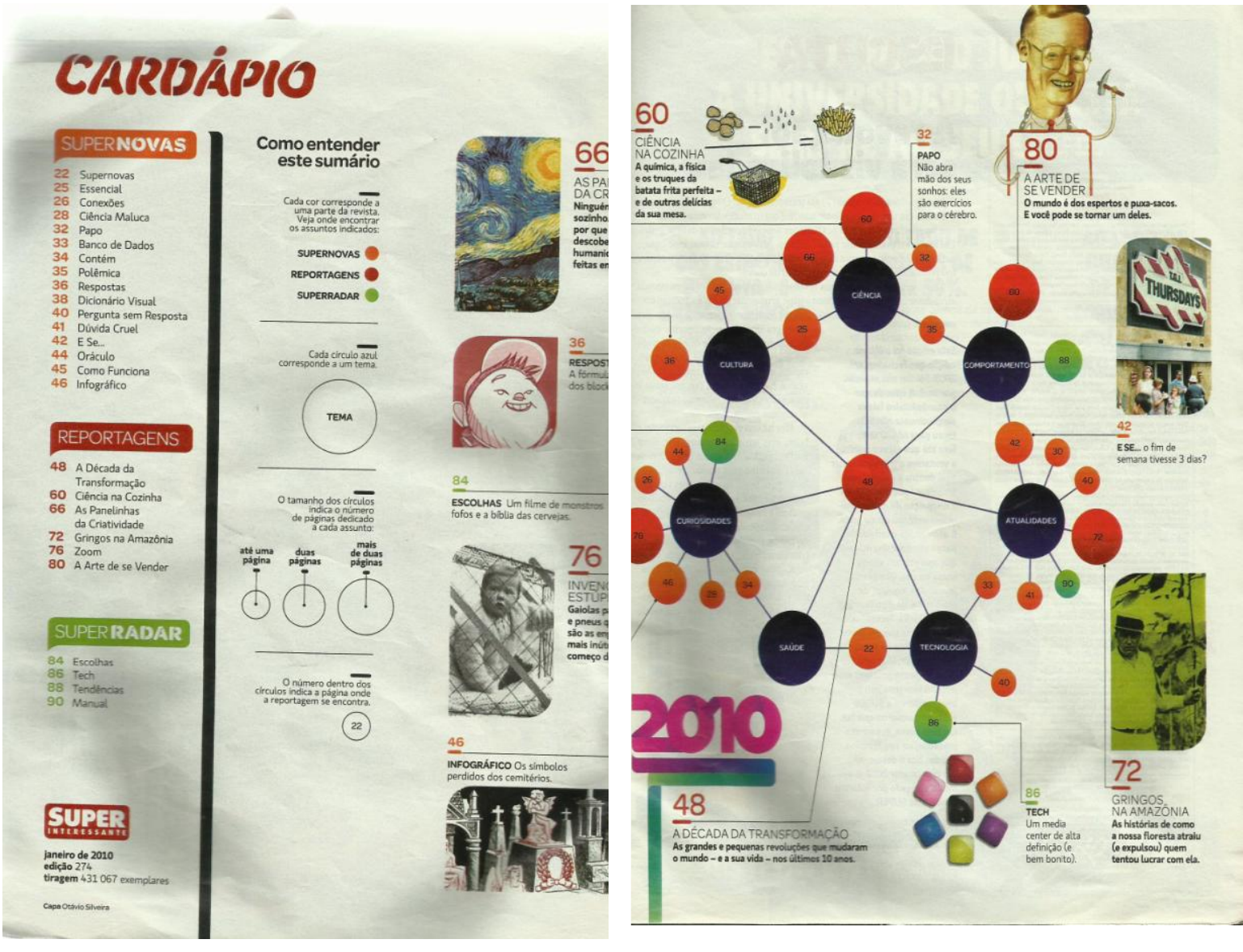

Figura 3 - Sumário edição 274 - Jan/2010.

\section{METODOLOGIA}

Considerando o objetivo da pesquisa de analisar como os leitores navegam em hipertextos no ambiente digital e impresso, algumas observações, com quatro voluntários que participaram de testes de navegação, foram realizadas. O perfil desses leitores diferiu em relação à idade, escolaridade e experiência com leitura nos dois ambientes.

Dos quatro participantes, duas têm mais de 70 anos, eram leitores de textos impressos e com pouca experiência em ambiente online. Os outros dois participantes, um com 27 e o outro 15 anos, ambos com muita experiência em atividades em ambiente online.

Os participantes se dispuseram a cumprir as tarefas sem pressa e o teste foi realizado cada um por vez em horários diferentes e dias diferentes. Para realização do teste, cada leitor tinha a tarefa de encontrar e ler uma matéria ${ }^{2}$ previamente 
escolhida, na revista impressa e depois online, cada versão por vez. A revista impressa foi apresentada a cada leitor sendo que podiam navegar livremente e cabendo a eles a narrar o trajeto de navegação, determinar o momento que encontrasse a matéria e o momento de encerrasse a leitura. Para a versão online da revista, foi apresentado um computador conectado à internet para que pudesse abrir o browser Google Chrome ou Internet Explorer e iniciar a busca pelo site da Revista Super Interessante e pela matéria solicitada. Foi cronometrado o tempo de cada tarefa e a observação ocorreu em um ambiente silencioso, em tempo real com registro das ações dos leitores com gravação através de uma câmera e anotações em caderno. A fim de identificar os perfis dos leitores foi realizada uma rápida entrevista inicial. Segue os resumos das respostas no quadro a seguir:

\section{QUADRO 1 - Perfis dos leitores participantes.}

\begin{tabular}{|c|c|}
\hline Leitores & Perfis \\
\hline Maria & $\begin{array}{l}15 \text { anos, estudante, tem muita experiência em leitura de texto } \\
\text { impresso e online, lê muitos livros impressos e online de ficção } \\
\text { Porém, pouca experiência em leitura de revista impressa. Declara } \\
\text { que prefere ler textos impressos, por gostar da sensação de pegar } \\
\text { no livro e sentir o cheiro do papel. }\end{array}$ \\
\hline Rodrigo & $\begin{array}{l}27 \text { anos, professor de inglês, tem muita experiência em leitura de } \\
\text { texto impresso e online, declara que lê dois textos online por dia. } \\
\text { Porém, pouca experiência em leitura de revista impressa. Declara } \\
\text { que prefere ler livros impressos, entretanto, tratando-se de outros } \\
\text { tipos de textos, prefere ler na tela. }\end{array}$ \\
\hline Aidé & $\begin{array}{l}73 \text { anos, aposentada, não costuma lê nem textos impressos e nem } \\
\text { digitais devido à sua vista que fica cansada. Tem tido contato com } \\
\text { computador por mais de um ano em um curso de informática. } \\
\text { Declara que prefere leitura em tela }{ }^{3} \text {, devido à luminosidade e a } \\
\text { vantagem de aumentar o tamanho da fonte. }\end{array}$ \\
\hline Marília & $\begin{array}{l}71 \text { anos, aposentada, tem pouca experiência em leitura de tanto } \\
\text { texto impresso quanto online. Declara que lê a bíblia impressa, que } \\
\text { tem um computador e o utiliza apenas para jogar. }\end{array}$ \\
\hline
\end{tabular}


Após a entrevista, os quatro leitores foram subdivididos em dois grupos de perfis, o grupo 1 (G1) formado por Maria e Rodrigo, participantes jovens e com muita experiência em textos impressos e online e o grupo 2 (G2), composto por Aidé e Marília, participantes idosas e com pouca experiência em textos impressos e online.

Em relação aos trajetos de navegação da revista impressa, considerei a análise dos testes com base em algumas categorias citadas por Ribeiro (2009, p.90) em seu trabalho sobre navegação e leitura em jornais impressos e online que são: escaniar a primeira página, nesse caso seria, escaniar o sumário da revista impressa e encontrar e ler a matéria. A matéria escolhida foi a "Códigos do além".

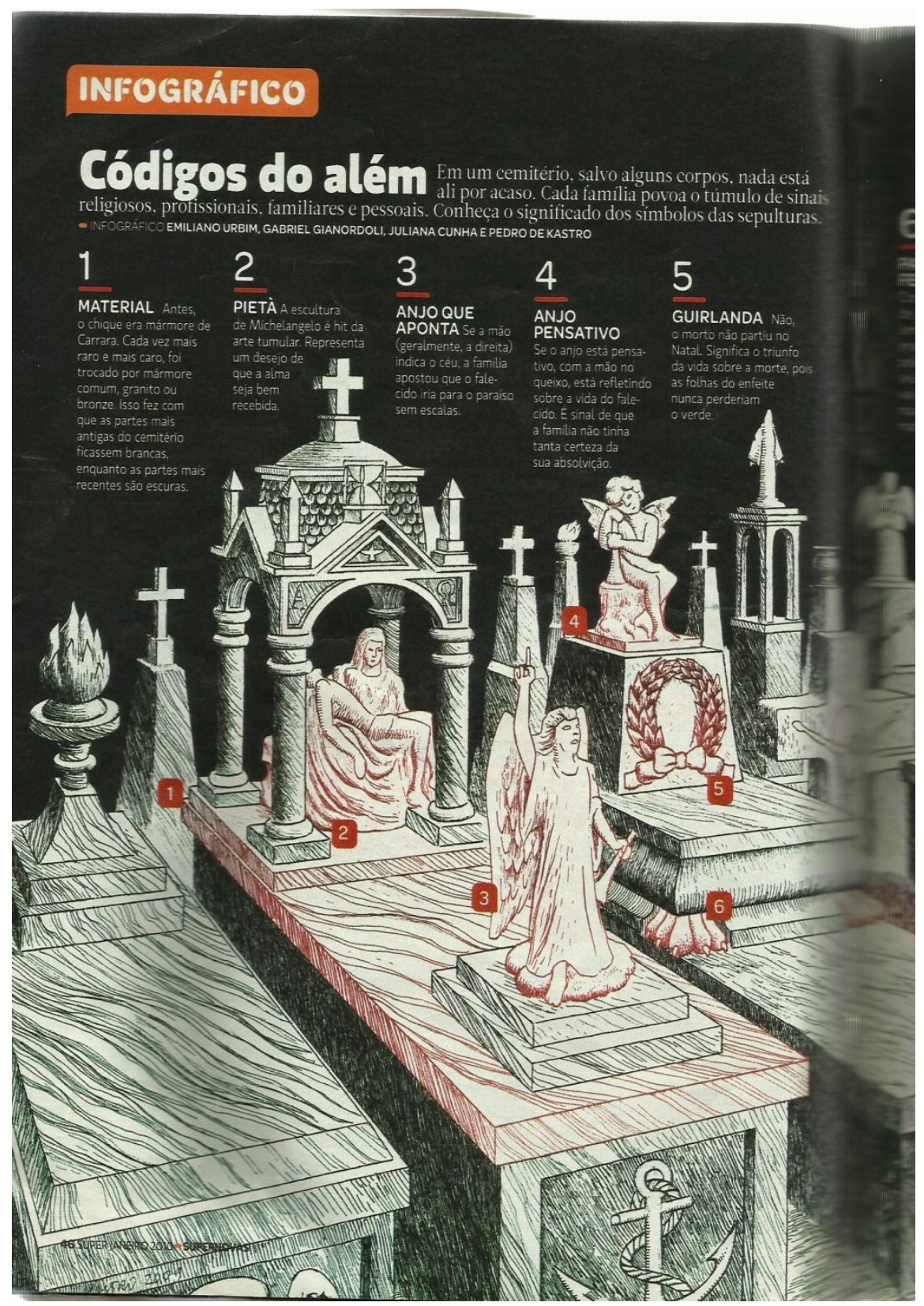




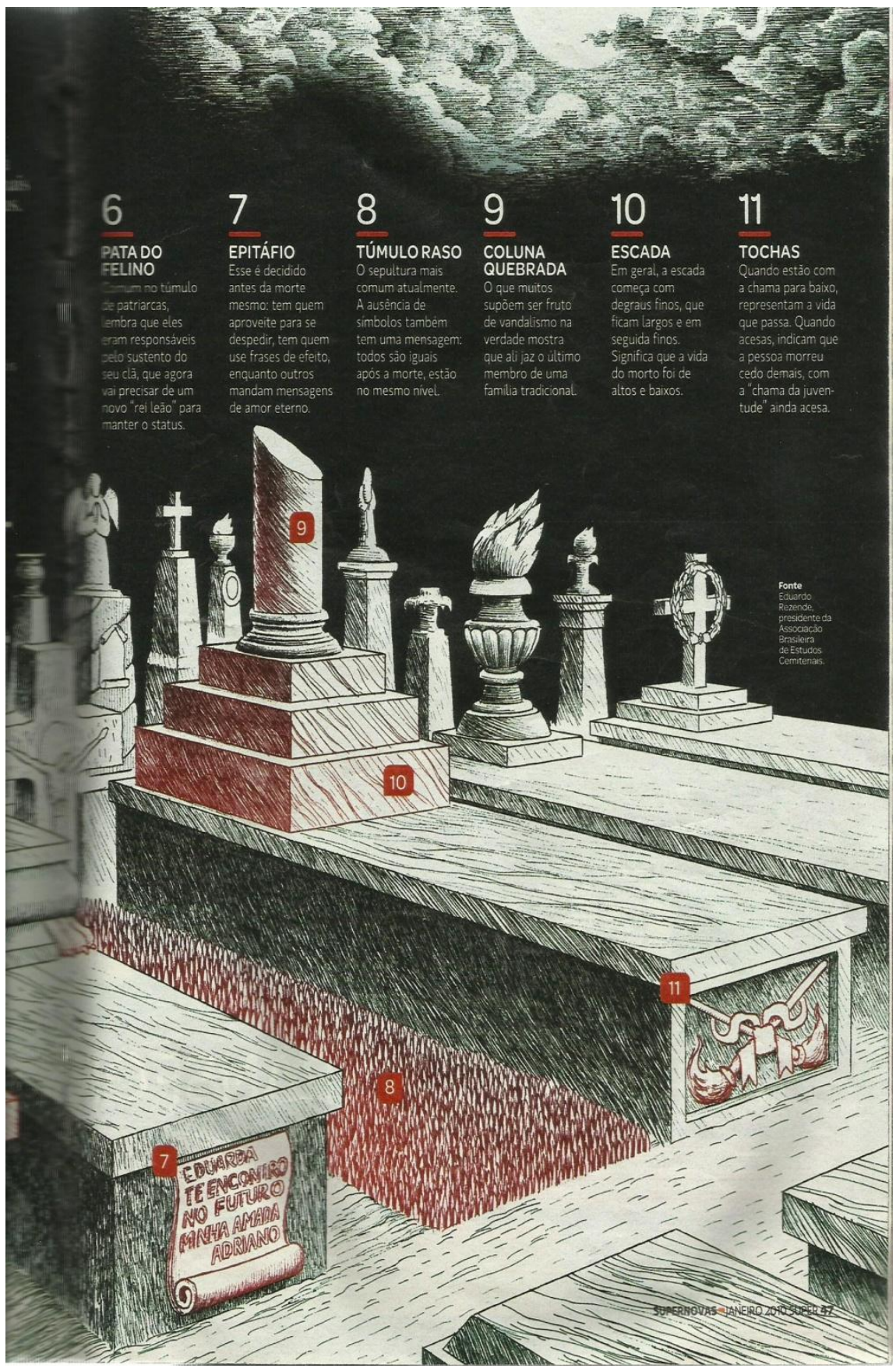

Figura 4 - Matéria sobre Códigos do além na Superinteressante impressa - Ed. 274, maio/2010. 


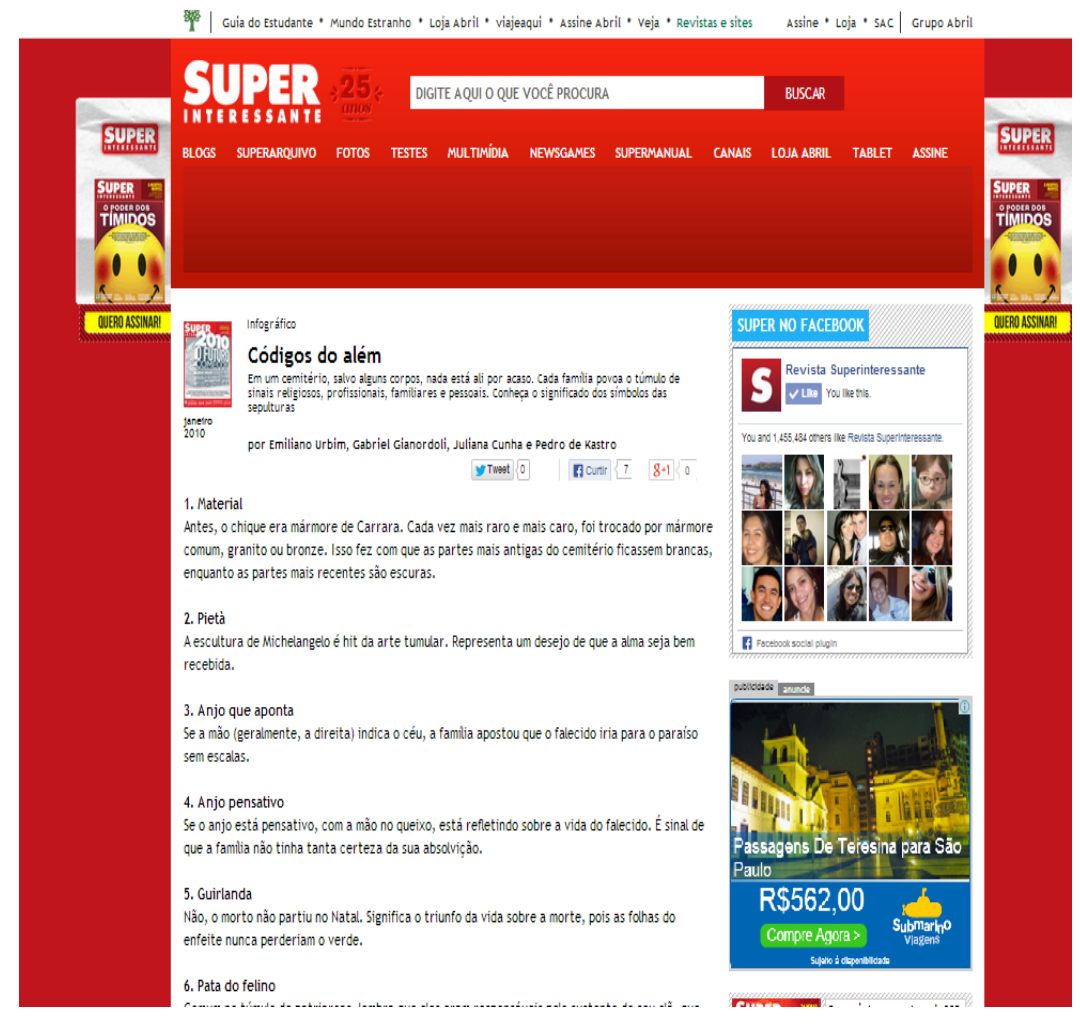

Figura 5 - Matéria sobre Códigos do além na Superinteressante online. Ed. 274, maio/2010.

Para encontrar a matéria exata é necessário fazer uma associação do título com as categorias de temas que aparecem no sumário da revista Super Interessante, pois nela o sumário é chamado de cardápio. Além disso, nem todos os títulos aparecem no cardápio. Para haver uma busca rápida, é necessário que o leitor tenha um conhecimento prévio da dinâmica da revista para ir pelo menos até o grupo de páginas aproximado do titulo procurado.

\section{ANÁLISE E RESULTADOS}

Durante os testes, observou-se que os todos os leitores faziam comentários em voz alta em relação ao conteúdo do texto e faziam inferências subjacentes à compreensão das leituras, porém como compreensão não esse não é o foco desse estudo não será aprofundado.

Todos os participantes demonstraram algum conhecimento desses ambientes. Mesmo o foco desse estudo sendo leitura de revista e alguns deles não sendo assíduos desse gênero, os leitores utilizaram seus conhecimentos prévios para fazer a busca. 


\section{G1 - participantes jovens e com muita experiência com textos impressos e online}

Na navegação, esse grupo apresentou bastante familiaridade com leituras nos dois ambientes, mesmo não tendo o hábito de leitura de revista impressa, esse grupo apresentou comportamento semelhante na navegação e leitura do texto online e impresso. A tarefa era encontrar e ler uma matéria sobre Códigos do além cemitérios. Os trajetos de navegação apresentados por Rodrigo e Maria foram bem semelhantes:

\section{Na revista impressa}

Navegação:

1. Olharam a página com uma figura bem grande com muitas cores chamativas, que fica localizada uma página antes do cardápio;

2. Em seguida fizeram uma varredura da página ${ }^{4}$ do cardápio;

3. Depois começaram a folhear da revista pausando em alguma página quando chamava a atenção deles até encontrar a matéria.

Maria encontrou em 2 minutos e Rodrigo em 1 minuto.

\section{Trajeto de leitura:}

1. Leram o título;

2. Leram o subtítulo;

3. Olharam a figura ${ }^{5}$;

Embora eles tenham encontrado o texto em pouco tempo, os dois provaram que não tem muita familiaridade com a revista impressa, pois não conseguiram localizar o texto no cardápio, o qual estava explicito com a figura. O texto apresentava onze tópicos, cada um falava sobre um código do além, ou seja, sobre os símbolos das sepulturas do cemitério e havia uma figura para representar cada símbolo. A leitora Maria, a cada tópico que lia olhava a figura na ordem até o numero onze, já o leitor Rodrigo, lia os tópicos fora de ordem, primeiro leu o numero 1 e 2 , quando percebeu que os tópicos não exigiam uma leitura linear, pulou para o ultimo, depois para o numero sete, aleatoriamente até finalizar a leitura. Durante a leitura silenciosa fizeram alguns comentários em voz alta como: "Nossa!", "Nossa, aqui tem um erro!", etc.

\section{Na revista online:}

\section{Navegação:}


1. Abriram o browser Google Chrome rapidamente e digitaram o nome da revista e clicaram no segundo link das opções sugeridas pelo Google;

2. Em seguida digitaram o nome do título "Códigos do além" na barra de pesquisa dentro do site, fizeram uma varredura na página, pois o site encontrou vários resultados com essa pesquisa e rapidamente encontraram a matéria. Maria abriu o texto em uma nova aba.

Maria encontrou o texto em 1 minuto e Rodrigo em 59 segundos.

\section{Trajeto de leitura:}

1.Leram o título;

2. Leram o subtítulo;

3.Começaram a ler os onze tópicos na ordem.

O texto na versão online não tem as figuras. Mas como do lado direto da tela tem várias fotos pequenas de perfil da rede social Facebook que "curtiram" o site da Super Interessante, Maria ficava intercalando a leitura com observação dessas pessoas. Segundo a leitora em entrevista, ela tirava os olhos do texto para olhar para a lateral porque o texto não tinha figuras e isso chamava a atenção dela. Já Rodrigo não olhou para a lateral da página online, mas antes de começar a leitura do texto moveu a barra de rolagem para ver o tamanho da matéria a ser lida. Ele relatou que toda vez que vai fazer uma leitura olha o tamanho do texto para ver se terá tempo de completar a leitura naquele momento.

\section{G2 - participantes idosos e com pouca experiência em textos impressos e online}

\section{Na revista impressa}

Navegação:

1. Folhearam as páginas até localizar o cardápio;

2. Em seguida fizeram uma varredura da página do cardápio;

3. Depois começaram a folhear a revista pausando em alguma página quando chamava a atenção delas até encontrar a matéria.

Aidé encontrou o texto em 3 e Marília em 2 minutos.

As leitoras também não conseguiram localizar o texto no cardápio e utilizaram a técnica de folhear a revista. Faziam vários comentários em voz alta como: "Cadê o índice?", "Hum, acho que não vou encontrar!" "Ah! Achei, aqui é cardápio!", "Não estou achando!", "Que letra horrível!", “Que lindeza!”. 


\section{Trajeto de leitura:}

1.Leram o título e refletiam sobre o título, faziam comentários em voz alta a respeito do tema;

2. Leram o texto;

3. Olharam a figura.

As duas participantes não leram o subtítulo e foram direto ao texto.

\section{Na revista online:}

As duas leitoras têm pouca habilidade de navegação nesse ambiente e os testes foram realizados com minha ajuda. Como elas não são "novatas" apenas facilitei a navegação guiando o passo seguinte quando necessário, mas elas que realizaram todo o processo.

\section{Navegação:}

1. Abriram o browser Google Chrome indicado por mim e digitaram o nome da revista;

2. Em seguida, escolherem o site da revista por mim entre as opções de resultados sugeridas pelo Google, clicaram e abriram a revista online;

4. Fizeram uma varredura na homepage movendo a barra de rolagem com o mouse clicando na seta da lateral direita da página procurando a matéria na página principal.

3. Depois, conduzidas por mim, digitaram o nome do título "Códigos do além" na barra de pesquisa dentro do site, fizeram uma varredura na página, pois o site encontrou vários resultados com essa pesquisa e encontraram a matéria.

Arena (2008, p. 28) afirma que:

Quando o leitor está familiarizado com um determinado tipo de texto, como o jornal, por exemplo, e conhece sua formatação, sua estrutura manchetes, título, olho, legenda, notícia, paginação, entre outros - poderá manipular qualquer jornal, seja ele de grande ou pequena circulação, até mesmo em língua desconhecida. Assim também ocorre com os meios eletrônicos.

Nessa pesquisa, as leitoras tinham familiaridade com textos de revista impressa, mas não foram bem sucedidas na manipulação da versão online, durante o teste elas faziam vários comentários em voz alta como: "O que eu faço agora?", “Onde eu digito?" "Onde está o acento agudo?”, "Eu digito lento mesmo!”. Elas não 
sabiam o próximo passo para efetuar a busca e se perderam, então guiei o processo do trajeto de navegação. Nesse contexto, Coscarelli $(2010$, p. 5) aponta que:

\begin{abstract}
$\mathrm{Na}$ navegação, o leitor precisa entender a sequência de links que leva a uma ação ou a um conteúdo. Se ele tem essa sequência apenas memorizada, mas não reflete sobre o sentido dela dentro das possibilidades do digital, poderá se perder e travar a navegação. Isso costuma acontecer porque o digital possui, assim como o impresso, uma gramática/sintaxe que Ihe é própria.
\end{abstract}

Marília gastou 7 minutos e Aidé gastou 16 minutos no processo de encontrar o texto solicitado.

\title{
Trajeto de leitura:
}

1. Leram o título e pausavam para fazer questionamentos sobre o conteúdo do texto em voz alta;

2. Leram o subtítulo;

3.Começaram a ler os onze tópicos na ordem.

Segundo Diniz et al. (2009, p. 29):

Quando um texto é materializado em determinado meio, as propriedades desse meio passam a compor as expectativas dos leitores. Quando tais expectativas não são cumpridas, há um descompasso inicial, mas o leitor, seja onde for, tende ao ajustamento.

Dessa forma, como a versão online o texto não tinha as figuras para relacionar o conteúdo, os símbolos do cemitério, a leitora Aidé recorreu à revista impressa para olhar a figura e durante a leitura ela lia na tela e olhava a figura na versão impressa. Houve comentários em voz alta como: “Acabei gostando!”, “Achei interessante!”. Na entrevista a participante Marília declarou ter preferência em leitura impressa pelo motivo de não ter intimidade com leituras em tela, porém durante o teste ela demonstrou mais interesse em ler na tela. Já na impressa, leu rapidamente e não olhou as figuras.

\section{ALGUMAS CONSIDERAÇÕES}

A experiência com trajetos de leitura e navegação mostrou que mesmo os leitores não assíduos em leitura de revista impressa, conseguem navegar com dentro dela e encontrar a informação desejada. Mas nenhum dos quatro leitores 
conseguiu localizar a matéria solicitada no cardápio da revista impressa. Essa ação me causou uma certa inquietação, surgindo a seguinte pergunta: Será que os participantes não conseguiram encontrar o texto no cardápio da revista impressa porque não são bons navegadores de textos impressos ou porque não estão acostumados com a dinâmica da revista Super Interessante?

Alguns achados me surpreenderam como o de a leitora idosa preferir leitura em tela devido à luminosidade e a vantagem de aumentar a fonte.

Em relação ao trajeto de leitura todos os participantes fizeram a leitura não linear e realizaram trajetos de navegação similares a leitores de mesmos perfis. Acredita-se que mesmo pelo fato de os meios digitais estarem inseridos na sociedade e que não existem leitores "novatos" nesses ambientes é preciso que os leitores com pouca experiência adquiram habilidades de navegação, as quais são imprescindíveis para uma busca efetiva. Observou-se que não é suficiente o meio digital estar inserido no dia-a-dia das pessoas para que elas façam um bom uso, a familiaridade com a interface é fundamental para a navegação em tela, pois como o G2 tem pouca familiaridade com leituras em tela, ficaram perdidos e não sabiam onde encontrar a barra para digitar o título e para prosseguir com a busca.

Outro ponto interessante é que os leitores assíduos com bastante experiência em diversos tipos de leitura impressa e digital preferem ler livros em formato impresso, devido aos mesmos motivos dos defensores da cultura impressa tais como: sentir o livro nas mãos e o seu cheiro, todavia preferem ler na tela os outros tipos de textos devido à facilidade de busca e navegação para encontrar a informação desejada.

Durante a análise e testes observou-se que os participantes faziam inferências a todo o momento demonstrando compreensão do texto, assim fica claro que a diferença do impresso para o digital não é a compreensão, mas sim os gestos de navegação e leitura.

Portanto essa pesquisa não encerra aqui e não tem o propósito de fazer conclusões, ainda há muitos resultados e observações a serem alcançados no contexto da sociedade e educação contemporâneas. 


\title{
NOTAS
}

${ }^{1}$ Mestranda em Linguistica Aplicada - Linguagem e tecnologia do Programa de Pós-Graduação em Estudos Linguísticos - POSLIN na Universidade Federal de Minas Gerais - UFMG. Email: vccingles@gmail.com

${ }^{2}$ A matéria encontra-se em anexo.

${ }^{3}$ Diferentemente desse dado, na pesquisa de Diniz et al. (2009, p. 29) a leitura em ambiente digital é apontada por um usuário como algo que o incomoda por causa da "letra pequena".

${ }^{4}$ A varredura (scanning) é a "olhadinha" que o leitor dá em seu primeiro contato com a página, Diniz et al. (2009, p. 26).

${ }^{5}$ A figura abrange a metade das duas páginas versão impressa, mas o mesmo texto na versão online não contém a figura.

\section{NAVIGATION AND READING OF DIGITAL HYPERTEXT AND PRINT}

\begin{abstract}
Based on the idea since the emerging of digital technologies in the modern society, social practices of reading has changed, this research presents an analysis of the browsing paths and reading in a printed and digital magazine. Reading tests were done with a group of readers. These tests have helped us understand how readers deal with different organizations of a text and how they behave during the reading process. Superinteressante Magazine was chosen for this study. In order to qualify for this research, observations were conducted during tests with readers followed by notes and recordings in real time. Theoretical support this study was based on Coscarelli $(2009,2010)$, Novaes (2009), Ribeiro (2009), among others. I present a survey of the experiment and it seems possible that even digital media are integrated in society and that there is no "new" readers in these environments, it is necessary that the readers with little experience acquire browsing skills which are essential for an effective search.
\end{abstract}

Keywords: Reading browsing. Digital and printed text. 


\section{REFERÊNCIAS}

ARENA, A. P. B. A leitura de jornais impressos e digitais em contextos educacionais: Brasil e Portugal. 2008. Tese (Programa de Pós-Graduação em Educação Faculdade de Filosofia e Ciências)-Universidade Estadual Paulista, São Paulo, 2008.

CAMPOS, G. P. C. O processo de leitura: da decodificação à interação. Revista Objetiva, Rio Verde, n. 4, 2008. Disponível em:

$<$ http://www.faculdadeobjetivo.com.br/view_sessao.php?id=59>. Acesso em: 5 fev. 2014.

COSCARELLI, C. Os dons do hipertexto. In: Littera: lingüística e literatura. Pedro Leopoldo: Faculdade de Ciências Humanas de Pedro Leopoldo, 2006.

COSCARELLI, C.; NOVAES, A. E. Leitura: um processo cada vez mais complexo. Letras de Hoje, Porto Alegre, v. 45, n. 3, p. 35-42, jul./set. 2010. Disponível em: $<$ http://revistaseletronicas.pucrs.br/fale/ojs/index.php/fale/article/view/8118http://revist aseletronicas.pucrs.br/fale/ojs/index.php/fale/article/view/8118/5807>. Acesso em: 5 fev. 2014.

. Letramento Digital. Presença Pedagógica, Belo Horizonte, v. 18, n. 103, p. 68-73, jan./fev. 2012.

DIAS, M. C.; NOVAIS, A. E. Por uma matriz de letramento digital. In: III ENCONTRO NACIONAL SOBRE HIPERTEXTO, 2009, Belo Horizonte. Anais... Belo Horizonte: CEFET-MG, 2009.

DINIZ, B. et al. Folheando de mentira: leituras de jornais impressos na web. Contemporânea, [s.I], v. 7, n. 1, jun. 2009.

DIONÍSIO, Â. P. 2006. Gêneros multimodais e letramento. In: KARWOSKI, Acir Mário et al. (Org.). Gêneros textuais: reflexões e ensino. 2. ed. Rio de Janeiro: Lucerna.

MAGDA, S. Novas práticas de leitura e escrita: letramento na cibercultura. Educação \& Sociedade, Campinas, v. 23, n. 81, p. 143-160, dez. 2002. Disponível em: $<$ http://www.cedes.unicamp.br>. Acesso em: 5 fev. 2014.

MARCUSCHI, L. A. O hipertexto como um novo espaço de escrita em sala de aula. Linguagem \& Ensino, V. 4, n. 1, p. 79-111, 2001.

RIBEIRO, A. E. Navegar lendo, ler navegando: aspectos do letramento digital e da leitura de jornais. 2008. Tese (Programa de Pós-Graduação em Estudos Linguísticos)-Universidade Federal de Minas Gerais, Belo Horizonte, 2008. 
PAIVA, F. A. O gênero textual infográfico: leitura de um gênero textual multimodal por gênero textual infográfico: leitura de um gênero textual multimodal por alunos da 1a série do ensino médio. L@el em (Dis-)curso, v. 3, 2011.

REVISTA SUPER INTERESSANTE. Tróia. São Paulo: Abril, maio 2004. Edição 200. . 2010: o futuro começou. São Paulo: Abril, jan. 2010. Edição 274.

REVISTA SUPER INTERESSANTE ONLINE. Disponível em: <http://super.abril.com.br/>. Acesso em: 12 maio 2013. 